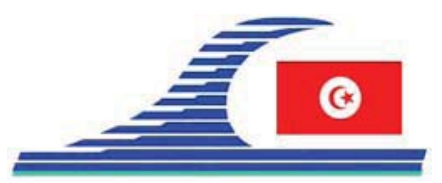

\author{
Conférence Méditerranéenne Côtière et Maritime \\ EDITION 1, HAMMAMET, TUNISIE (2009) \\ Coastal and Maritime Mediterranean Conference \\ Disponible en ligne - http://www.paralia.fr-Available online
}

\title{
Characterization of the mechanical properties of dredged marine sediment stabilized by fly ash
}

\author{
Ernesto SILITONGA ${ }^{1}$, Salim MEZAZIGH ${ }^{1}$, Daniel LEVACHER ${ }^{1}$ \\ 1. University of Caen, UMR CNRS 6143 M2C, 14000 Caen, France. \\ ernesto.silitonga@unicaen.fr
}

\begin{abstract}
:
A solution to the disposal of large volume of dredged sediments is by reuse these materials as fills for land reclamation or in road construction. The aim of this study is to identify the influence of fly ash as a binder on the mechanical properties of stabilization of dredged sediment. In order to complete the environmental analysis, mechanical properties are studied in this paper, with usual geotechnical parameters on road construction (particle size analysis, Proctor normal, California bearing ratio, unconfined compressive strength).
\end{abstract}

\section{Keywords:}

Dredged sediment - Fly ash - California bearing ratio - Unconfined compressive strength

\section{Introduction}

Fly ash is used in a number of countries for stabilization of soils. It should be pointed out that the both the nature of the fly ash and the type of soil influence the results of stabilization and to rely on research carried out with different soil and fly ash is not practically safe. In this study the fly ash is used to stabilized the dredged sediment in order to study the potential reuse of dredged sediment as a material backfill and in road construction. The previous experiments used cement and lime as a binder (ZENTAR et al.). In order to achieve effectiveness of fly ash on soil stabilization work, by trying to make a more productive use of fly ash would have considerable environmental benefits, reducing air and water pollution.

\section{Materials and experimental details}

The dredged sediment from Port of Cherbourg, France, were used in this experiment. Two different types of fly ash (FA), named Sodeline (SD) and Soproline (SPRL) were added in the mixture

\subsection{Particle size}

To characterize the particle size distribution (PSD) of the dredged sediment and the fly ashes, a laser diffractometer Coulter LS2000 was used. Mehta (MEHTA, 1985) reported DOI: $10.5150 / \mathrm{cmcm} .2009 .039-Y$ 
that the particles larger than $45 \mu \mathrm{m}$ show little or no reactivity under normal hydration conditions and the pozzolanic activity was directly proportional to the amount of particles under $10 \mu \mathrm{m}$. From table 1, we can observe that Sodeline has coarse particles $(>45 \mu \mathrm{m}) 1.6$ times $(21.04 \%)$ than Soproline (12.78\%) but in the same time Sodeline $(35.49 \%)$ has 1.35 times fine particles $(<10 \mu \mathrm{m})$ than Soproline $(26.25)$. From this particle size point of view, we expect that Soproline will be more reactive than Sodeline.

Table1. Characteristic diameters and fraction of materials.

\begin{tabular}{lllllll}
\hline Particle size & $\boldsymbol{D}_{\mathbf{1 0}}(\boldsymbol{\mu m})$ & $\mathbf{D}>\mathbf{4 5}(\boldsymbol{\mu m})$ & $\mathbf{D}<\mathbf{1 0}(\boldsymbol{\mu m})$ & $\begin{array}{l}\text { Clay (\%) } \\
<2 \boldsymbol{\mu m}\end{array}$ & $\begin{array}{l}\text { Silts (\%) } \\
\mathbf{2} \text { to } \mathbf{6 3} \boldsymbol{\mu m}\end{array}$ & $\begin{array}{l}\text { Sand (\%) } \\
>\mathbf{6 3} \boldsymbol{\mu m}\end{array}$ \\
\hline Dredged sediment & 172.4 & 43.76 & 13.60 & 4.52 & 56.6 & 38.88 \\
Cement & 729.6 & 32.78 & 20.51 & 15.23 & 53.30 & 31.47 \\
Sodeline & 68.23 & 21.04 & 35.49 & 10.17 & 79.36 & 10.47 \\
Soproline & 48.17 & 12.78 & 26.25 & 7.34 & 88.87 & 3.79 \\
\hline
\end{tabular}

\subsection{Mix design}

To study the influence of the fly ash, samples with different fly ash content were made. The different formulas in this experiment are given in table 2.

Table2. Different compositions of binders

\begin{tabular}{llllll}
\hline & Name & Sodeline (\%) & Soproline (\%) & Lime (\%) & Cement (\%) \\
\hline \multirow{3}{*}{ FA-L-C } & SD 1 & 4 & - & 3 & 2 \\
& SD 2 & 10 & - & 3 & 2 \\
& SPRL 1 & - & 4 & 3 & 2 \\
& SPRL 2 & - & 8 & 3 & 2 \\
\hline Hydraulics binders & HB & - & - & 3 & 2 \\
\hline
\end{tabular}

\section{Results and discussions}

\subsection{Effect of fly ash on compaction Proctor test}

As shown in figure 1 , the optimum moisture content $\mathrm{w}_{\mathrm{opt}}$ for untreated dredged sediment is the minimum (23\%) among the others specimens and the optimum moisture content $\mathrm{w}_{\text {opt }}$ increase along with the increase of binder content. Due to the lower specific gravity of the binder (fly-ash) than that of the dredged sediment, the maximum dry density decreased and with the increasing of fly-ash contents meanwhile the optimum moisture content increased with increasing fly ash content. The optimal moisture content optimal obtained with addition of 4\% of fly ash for SD1 is 24.9 and 25.3 for SPR1 and with the addition of $8 \%$ of fly ash, SD2 obtained 29.1 and 29.6 for SPRL2 . The addition of binder changes the porosity and void ratio within the range of void ratio of fly ash, cement and soils. At maximum, the void ratio and porosity are free from 
moisture content. At the bulk density under compaction, the void ratio of the sediment and the porosity are minimum.

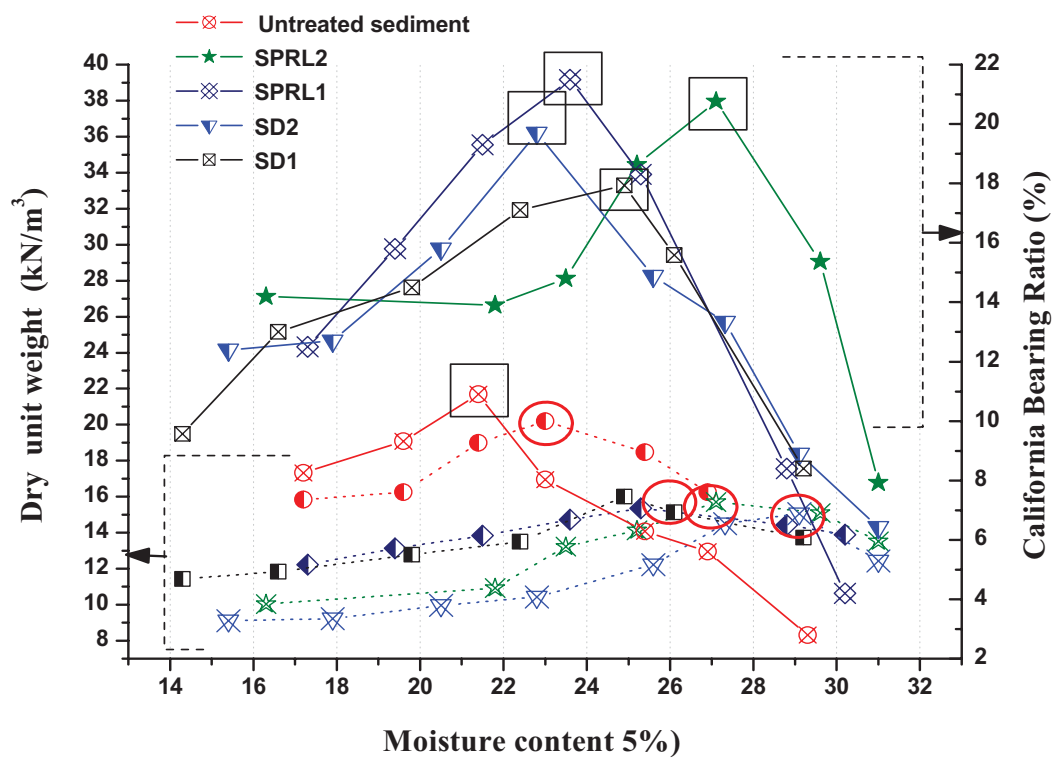

Figure1. Effect of solidified samples with different type and concentration of fly ash on California bearing ratio (CBR).

On the other hand, the optimum moisture content $\mathrm{w}_{\mathrm{opt}}$ increase with the increase of the binder.

\subsection{Effect of fly ash on California bearing ratio (CBR)}

The results of California bearing ration (CBR) test clearly show that the addition of fly ash has influenced the CBR value. The improvement of soil strength in CBR due to the function of soil-fly ash interlocking phenomena. The CBR value of untreated sediment is 10.9 , and by adding $4 \%$ of fly ash the CBR values are increased up to 17.9 (Sodeline) and 19.7 (Soproline). The results with addition of $8 \%$ of fly ash still shows that the CBR value obtained with Soproline (20.3) is still better than Sodeline (19.7). The different particles size of each fly ash can be the explanation of this result. The influence of the finer particle size of fly ash produces more reactive pozzolanic reaction because smaller particle size of fly ash with a higher surface area and glassy phase content also improved the pozzolanic reaction.

\subsection{Unconfined compressive strength (U.C.S)}

The U.C.S of soil is considerably one of the most important designing parameters for pavement design highway construction. As shown in figure 1, at curing period before 30 days, the UCS values between HB (without fly ash) and other samples (with fly ash) is 
not very large, We assumed at this curing period, the pozzolanic reaction was not completely achieved to provide the additional strength gain. We can assume that the strength gain is provided by the hydration of small amount of cement $(2 \%)$ and lime $(3 \%)$ in each sample. The hydration of the cement gives a rapid strength gain, while the lime generates heat which accelerates the cementitious and pozzolanic reaction. The hydration of the lime also produces large amounts of $\mathrm{Ca}(\mathrm{OH})_{2}$, required for the slower pozzolanic reaction in fly ash and for ion exchange in clays. The UCS values after 60 days of curing period, the strength value of the specimens with Soproline (SPRL1 and SPRL2) obtained less than specimens with Sodeline (SD1 and SD2) this result shows that the Sodeline more reactive as a binder than Soproline. At this age the reaction pouzzolanique is more depending on its chemical properties.

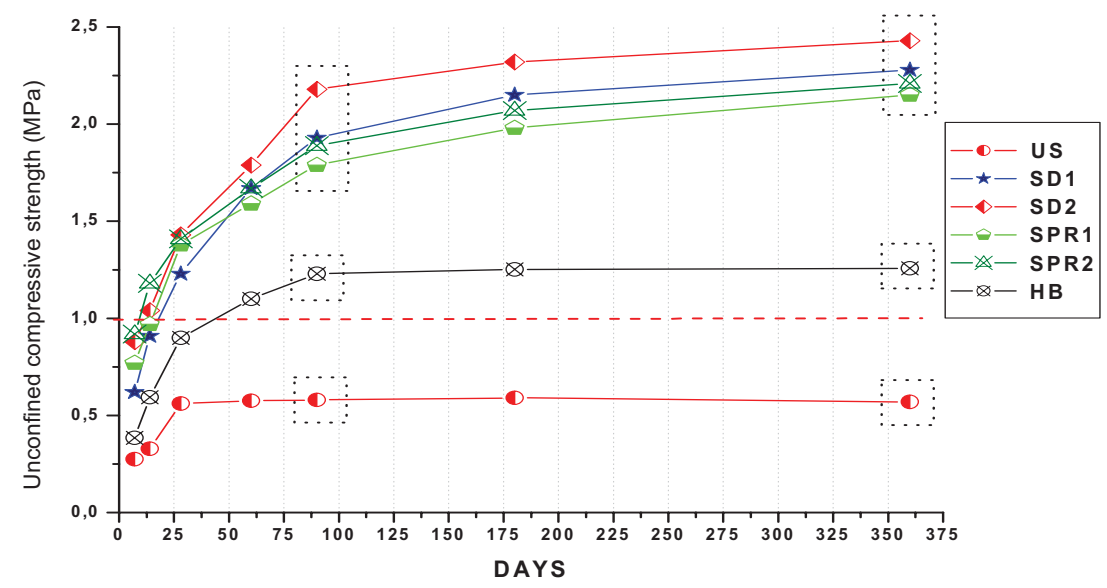

Figure 2. Effect of solidified samples with different type and concentration of fly ash on U.C.S development of at different curing ages

\section{Conclusions}

The experiments conducted to study the effect of fly ash in stabilization of dredged sediment. Based on the study presented in this paper the following conclusions are made. Addition of FA improves the CBR values, but increase the amount of water needed. The addition of FA also improves the UCS value by accelerating the hydration of cement (at 7-14 days curing periods) and providing the additional strength after due to its pozzolanic reaction (after 60 days curing period).

\section{References}

ZENTAR R., DUBOIS V., ABRIAK N.E. (2008). Mechanical behaviour and environmental impacts of a test road built with marine dredged sediments. Resource, Conservation and Recycling 52, pp 947-954.

MEHTA P.K. (1985). Influence of fly ash characteristics on the strength of Portland cement-fly ash mixtures. Cement and Concrete Research, vol.15, PP. 669-674. 